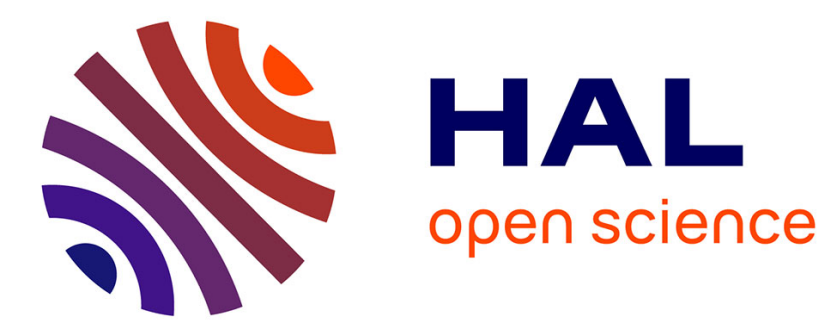

\title{
Influence of asymmetric etching on ion track shapes in polycarbonate
}

\author{
M.-C Clochard, Travis L Wade, J.-E Wegrowe, Emmanuel Balanzat
}

\section{To cite this version:}

M.-C Clochard, Travis L Wade, J.-E Wegrowe, Emmanuel Balanzat. Influence of asymmetric etching on ion track shapes in polycarbonate. Nuclear Instruments and Methods in Physics Research Section B: Beam Interactions with Materials and Atoms, 2007, 265 (1), pp.325-329. 10.1016/j.nimb.2007.08.065 . hal-01129024

\section{HAL Id: hal-01129024 https://hal.science/hal-01129024}

Submitted on 11 Mar 2015

HAL is a multi-disciplinary open access archive for the deposit and dissemination of scientific research documents, whether they are published or not. The documents may come from teaching and research institutions in France or abroad, or from public or private research centers.
L'archive ouverte pluridisciplinaire HAL, est destinée au dépôt et à la diffusion de documents scientifiques de niveau recherche, publiés ou non, émanant des établissements d'enseignement et de recherche français ou étrangers, des laboratoires publics ou privés. 


\title{
Influence of asymmetric etching on ion track shapes in polycarbonate
}

$\underline{\text { M-C. Clochard }}^{1)}$, T.L. Wade ${ }^{1)}$, J-E. Wegrowe ${ }^{1)}$, E. Balanzat $^{2)}$

1) Laboratoire des Solides Irradiés, Ecole Polytechnique, CEA/DSM, CNRS, F-91128 Palaiseau, France.

${ }^{2)}$ CIRIL, Unité mixte CEA-CNRS-ENSICAEN, F-14070 Caen Cedex 5, France

* corresponding author : marie-claude.clochard@polytechnique.edu

\begin{abstract}
By combining low-energy ion irradiation with asymmetric etching, conical nanopores of controlled geometry can be etched in polycarbonate (PC). Cone bases vary from 0.5 to $1 \mu \mathrm{m}$. Top diameters down to $17 \mathrm{~nm}$ are reached.. When etching from one side, the $\mathrm{pH}$ on the other side (bathed in neutral or acidic buffer) was monitored. Etching temperature ranged from $65^{\circ} \mathrm{C}$ to $80^{\circ} \mathrm{C}$. Pore shape characterization was achieved by electro replication combined with SEM observation. The tip shape depended on whether an acidic buffer was used or not on the stopped side.
\end{abstract}

PACS: 61.41+e, 61.46df, 61.80Jh, 41.75.-i

Keywords: conical pores, track-etched membranes, electrodeposition

\section{Introduction}

Template synthesis can be considered as an alternative to conventional lithography methods. It is one way of providing a panel of nanoscale metallic wires, tubes or organic polymeric devices [1-7]. Our interest is focused on track-etched membranes produced from swift heavy ion bombardment of 
polymer films [8]. In comparison with self-assembly of block copolymers, this bottom-up approach has the advantage of being economic, it is not time-consuming and it allows track formation of diverse geometries. Tailoring of the conical nanopore tip opening would have a tremendous impact on sensing domain [9], as well as on fundamental understanding of perpendicular Giant Magneto Resistance (GMR) properties observed in metallic homogeneous and multilayered cylindrical nanowires [1, 10$11]$.

The starting point of the track formation process is the transfer of energy from the projectile-ion to the target electrons and nuclei [12-14]. The energy deposited per unit track length is well known as energy loss function $(\mathrm{dE} / \mathrm{dx})$ or stopping power $\mathrm{S}(\mathrm{E})(\mathrm{S}(\mathrm{E}) \equiv \mathrm{dE} / \mathrm{dx})$. Figure 1 gives a qualitative shape of the energy-loss function for a projectile-ion in a solid containing the basic features of all energy-loss curves.

At low ion energies of $0.1 \mathrm{MeV} / \mathrm{amu}$, shortly before the end of the ion track, nuclear stopping becomes prevalent. This is due to the ion slow down to approximately Bohr velocity. At higher energies, the energy-transfer to the individual electrons of the irradiated solid prevails. This general description should be a little moderated with polymers at low energy. Indeed, even if Lee et al. [15] confirmed a significant increase in nuclear events at $0.1 \mathrm{MeV} / \mathrm{amu}$ compared to $1 \mathrm{MeV} / \mathrm{amu}$ when studying a polypropylene polymer foil under Ar ion beam, he also showed that a non-negligible electronic Linear Energy Transfer (LET) occurs simultaneously at the critical value of $0.1 \mathrm{MeV} / \mathrm{amu}$.

The low energy ion beam provided by the IRRSUD beam line at GANIL allows us to irradiate polymer foil with heavy ions such $\mathrm{Pb}$. The swift heavy ions pass through the polymer film with a starting energy of $0.63 \mathrm{MeV} / \mathrm{amu}$ and a final energy of $0.1 \mathrm{MeV} / \mathrm{amu}$. The physical response in polymer in view of energy deposition depends on nuclear and electronic stopping and on the local density of the electronic energy deposition. This density is determined by both the projectile velocity and the electronic stopping power. Schematically, sparse electronic irradiation density, for instance in the halo of the tracks, favors cross-linking whereas dense electronic irradiation density (track core) or nuclear processes enhance 
chain scission. Such properties should have a significant impact on track etch rate from one side of polymer film to the other side leading to conical-shaped nanopore. The aim of the work is to propose a simple way to obtain conical nanopores in PC membranes of diverse conicities by combining lowenergy heavy ion beam radiation effects with asymmetric etching.

\section{Experimental}

The Swift Heavy Ions (SHI) irradiations were performed with the IRRSUD beam line at GANIL (Caen, France). $10 \mu \mathrm{m}$ thick PC films were irradiated with Pb ions (0.633 Mev/amu; Fluence, $10^{8}$ ions $/ \mathrm{cm}^{2}$ ) under vacuo. Track etched PC membranes were obtained by asymmetrical chemical etching of the latent tracks in $2 \mathrm{~N} \mathrm{NaOH}$ using a two compartment cell assembly. The two compartments are separated by the irradiated PC film. The whole assembly is immersed in a thermostated bath. One compartment is equipped with a dual $\mathrm{pH} /$ temperature probe allowing us to monitor the tip pore opening. Various temperatures from $65^{\circ} \mathrm{C}$ to $80^{\circ} \mathrm{C}$ and various etching time were investigated. Prior to electrodeposition, track etched PC membranes were metallised with a thin layer of $\mathrm{Au}$ and fixed on a metallic support. The electrolyte $\mathrm{NiSO}_{4}: 5 \mathrm{H}_{2} 0$ solution $(130 \mathrm{~g} / \mathrm{L})$ was used to deposit Nickel. A potential of -1 V versus Saturated Calumel Electrode was applied for 1000s, using a Heka PG310 potentiostat. An increase in cathodic current intensity assesses the complete pore filling. PC membranes were dissolved for $15 \mathrm{~min}$ at room temperature using dichloromethane. The pore shape characterization was achieved by electronic microscopy measurements on membrane surfaces and on electrodeposited nanowires. SEM micrographs were carried out with a Philips apparatus equipped with a LaB6 tip (LMS, Ecole Polytechnique).

\section{Results and Discussion}

\subsection{Etch-rate / Pore opening}


PC films were irradiated with low energy $\mathrm{Pb}$ ions. One face of the film (entry face) received 0.63 MeV/amu $\mathrm{Pb}$ ions and the other side (exit face) yielded only $0.1 \mathrm{MeV} / \mathrm{amu} \mathrm{Pb}$ ions. These energetic differences between the entry and exit faces lead to different damages according to theory. Indeed, as pointed out from Figure 2, both faces are not equivalently etched under the same conditions. The entry face displays larger pore diameters than the exit face. It witnesses a higher sensitivity versus the etching process. Several differences in the energy deposition on entry and exit faces could have antagonist effects. Nuclear stopping prevails at the exit face. It is of the same order of magnitude than the electronic stopping. The electronic stopping power is lower in the exit face than in entry face; 4,9 $\mathrm{keV} / \mathrm{nm}$ and $10.8 \mathrm{keV} / \mathrm{nm}$ respectively. The projectile velocity is lower at the exit face than hence the fraction of the electronic energy deposited in the core track is higher. Radial dose calculations indicate the $90 \%$ and $60 \%$ of the electronic energy loss are deposited in a $5 \mathrm{~nm}$ radius for the exit and entry faces respectively. The experiments show that the higher electronic deposition in the entry face makes latent tracks more etchable.

The radial etch rates for the entry face and the exit face of the polymer membranes both sides in contact with etch solutions are estimated to be around $13 \mathrm{~nm} / \mathrm{min}$ and $9.3 \mathrm{~nm} / \mathrm{min}$ respectively. It illustrates that the differences are in the same order of magnitude and it allows us to modulate the energy impact factor on the conicity variation of the resulting track etched nanopores.

The major factor driving the conical nanopores shape in this experiment is that the etching is applied on one side of the PC film. This asymmetric etching is $\mathrm{pH}$-monitored from the non-etched side. $\mathrm{pH}$ curves versus etching time (Figure 3) reveal the break through when all pores open. As the temperature increases, the time necessary for the pore tip to open is reduced and the $\mathrm{pH}$-jump becomes sharper. It implies that the etch rate inside the latent track increases with the temperature. The role of the temperature is even more important in the case of lower energy face etching. Indeed, a gap in peak sharpness between $70^{\circ} \mathrm{C}$ and $80^{\circ} \mathrm{C}$ shows a significant improvement in latent track sensitivity. Energy transferred by temperature may then allow tracks to further weaken the exit zone. The delay in tip pore 
opening time between the higher and lower energy face assess to the chaotic state of $0.1 \mathrm{MeV} / \mathrm{amu}$ latent track side. Moreover, it is likely that the poor energy at the exit may lead to a substantial energy straggling at the exit face due to polymer structural heterogeneities.

The derivative signal of the $\mathrm{pH}$-jump allows us to appreciate directly the pore tip opening distribution (Figure 4). It is important to notice that most times a sharp peak was obtained followed by a less dramatic decrease. By integration of each peak contribution from deconvoluted signals, we estimate that $70 \%$ of the pores open simultaneously and $30 \%$ continue to open after the break through. This was already observed in multi-track membranes [16]. It means that some latent tracks contain slight differences in composition. As we previously mentioned, it may come from structural heterogeneities in the semi-crystalline polymer composition. In order to narrow down the tip-pore size distribution, we have added a neutralizing solution, an acidic buffer, to the non-etched side. It permitted to delay tip pore opening of the most sensitive latent tracks.

\subsection{Track shape}

The energy loss mechanism of the projectile-ions leads to electronic and atomic collision-cascades along the ion pathway forming the latent tracks. While the electronic collision-cascade has a long range (halo), the latent track can be considered, in a first approximation, as a cylindrical zone of few $\mathrm{nm}$ diameter with locally highly damaged core of increased etch-rate. As track etch rate is usually a monotonous function of the energy loss function $(\mathrm{dE} / \mathrm{dx})$, the shape of etched track depends mainly on the ratio of the track etch rate in the activated zone and the etch-rate in the undamaged material. If we assume two distinct domains of the solid, on one hand the undisturbed bulk material and on the other hand the latent track, the evolution of track shape during etching can be simulated by drawing spheres according to Huygen's construction to represent the etching wave-front along a virtual x-axis (Figure 5). 
When we use a neutralizing solution in the second compartment of the cell assembly to delay the pore tip enlargement, the etching solution is mixed with the acidic solution as the tip pore opens. Then, a second wave-front of diffusional type is created in the opposite x-direction. Consequently, it slows down the track etch-rate. The etching front changes from a constant rate to a decreasing one (Figure 2). It explains the shape of the Ni nanowires (Figure 6B). When no neutralizing solution is used, the etch rate remains constant and electrodeposited $\mathrm{Ni}$ nanowires display regular sting shape cones (Figure 6A).

\subsection{Conicity}

Calculation of the cone angle $\alpha$ was possible from nanowire track replicas (Scheme 2). Indeed, the electrodeposition of metallic ions inside the track etched PC membranes nanopores is an excellent means to replicate the tracks. Determining two diameters $\mathrm{x}_{1}$ and $\mathrm{x}_{2}$ separated by a distance $\mathrm{d}$, $\alpha$ is

expressed as follows: $\alpha=2 \arctan \left(\frac{x_{1}-x_{2}}{2 d}\right)$. A tip pore opening value, $\mathrm{x}_{\mathrm{f}}$, is also extrapolated from electrodeposited nanowires: $X_{f}=B-\frac{e\left(x_{1}-x_{2}\right)}{d} \quad$ where $\mathrm{B}$ is the cone base corresponding to the pore diameter of PC track-etched membrane and e is the membrane thickness.

As summarized in table 1, cone angles are small. Figure 7 illustrates needle shaped nanowires. In order to keep a pore fluence similar from one face to another, etching time should be stopped when the $\mathrm{pH}$ plateau is reached. It is possible to obtain pore tip openings inferior of $17 \mathrm{~nm}$ in $9 \mu \mathrm{m}$ thick membranes by stopping the etching process just at the break through appearance but with a significant decrease in pore fluence.

\section{Conclusion}

To vary the conicity of nanopores, we have combined etch rate variations due to stopping and asymmetric etching. According to the chaotic state of lower energy face, it is advisable to etch 
preferentially the higher energy face to get a better control on final conical pore shape. Asymmetric etching is a simple way to get conical shaped nanopores with a pore tip as low as $17 \mathrm{~nm}$ in $9 \mu \mathrm{m}$ thick membranes. Reaching smaller pore tip diameters may be absolutely possible when stopping the etching at the beginning of the break through. Nevertheless, pore fluence at the exit face would drop dramatically.

\section{References}

[1] T. L. Wade, J.-E. Wegrowe, Eur. Phys. J. Appl. Phys. 29 (2005) 3

[2] C. J. Hawker, T. P. Russell, MRS Bulletin 30 (2005) 952

[3] C. Schönenberger, B. M. I. Van der Zande, L. G. J. Fokkink, M. Henny, C. Schmid, M. Krüger, A. Bachtold, R. Huber, H. Birk, U. Staufer, J. Phys. Chem. B 101 (1997) 5497

[4] E. Ferain, R. Legras, Radiation Measurements 34 (2001) 585

[5] L. Dauginet-De Pra, E. Ferain, R. Legras, S. Demoustier-Champagne, Nuclear Instruments and Methods in Physics Research B 196 (2002) 81

[6] L. T. Cai, H. Skulason, J. G. Kushmerick, S. K. Pollack, J. Naciri, R. Shashidhar, D. L. Allara, T. E. Mallouk, T. S. Mayer, J. Phys. Chem. B. 108 (2004) 2827

[7] M.-C. Clochard, C. Baudin, N. Betz, A. Le Moel, C. Bittencourt, L. Houssiau, J.-J. Pireaux, D. Caldemaison, Reactive and Functional Polymers In Press, Corrected Proof

[8] M. Grasselli, N. Betz, Nucl. Instr. and Meth. B 236 (2005) 501

[9] C. C. Harrell, Z. S. Siwy, C. R. Martin, Small 2 (2006) 194

[10] J.-E. Wegrowe, S. E. Gilbert, D. Kelly, B. Doudin, J.-P. Ansermet, IEEE Trans. Magn. 34 (1998) 903

[11] Fert, Piraux, JMMM 200 (1999) 274

[12] R. Katz, S. C. Sharma, M. Homayoonfar, The Structure of Particle Tracks, Academic Press, New York, 1972

[13] R. L. Fleischer, P. Price, R. M. Walker, Nuclear Tracks in Solids, Univ. of California Press, Berkeley, 1975

[14] R. Spohr, Ions Tracks and Microtechnology. Principles and Application., Friedr. Vieweg\&Sohn Verlegsgschaft mbH, Braunschweig, 1990

[15] E. H. Lee, Nucl. Instr. and Meth. Phys. Res. B. 151 (1999) 29 
[16] L. Q. Peng, P. Y. Apel, Y. Maekawa, M. Yoshida, Nuclear Instruments \& Methods in Physics Research Section BBeam Interactions with Materials and Atoms 168 (2000) 527

\section{Figure captions}

Scheme 1. Geometry of conical pore

Figure 1: Schematic stopping function $\mathrm{S}(\mathrm{E})$ of a projectile-ion in solid matter as a function of the kinetic energy $E$ of the projectile-ion [14].

Figure 2. Pore diameters estimated by SEM versus etching time. Etch conditions: $70^{\circ} \mathrm{C}, \mathrm{NaOH} 2 \mathrm{~N}$.

Exit face in contact with etch solution, $\square$ Entry face in contact with water, $\circ$ Exit face in contact with water, $\bullet$ Entry face in contact with etch solution

Figure 3. pH versus etching time curves at $(\square) 65^{\circ} \mathrm{C},(\bullet) 70^{\circ} \mathrm{C},(\boldsymbol{\Delta}) 75^{\circ} \mathrm{C}$ and $(\boldsymbol{\bullet}) 80^{\circ} \mathrm{C}$.

Figure 4. $\mathrm{pH}$ versus etching time curves of $0.63 \mathrm{MeV} / \mathrm{amu} \mathrm{PC}$ membrane face and its derivative at $70^{\circ} \mathrm{C}$.

Figure 5: Typical etch figures for (a) increasing, (b) constant and (c) decreasing etch-rate. The crosses mark the center of the spherical "waves" emitted at equal time intervals [15].

Figure 6: Electrodeposited Ni conical nanowires (base diameter: $800 \mathrm{~nm}$; top diameter: $100 \mathrm{~nm}$; length $7 \mu \mathrm{m})$ after dissolution of metallized track-etched PC membrane. PC films were irradiated with $\mathrm{Pb}$ of $0.63 \mathrm{MeV} / \mathrm{amu}$. Etching conditions: Asymmetrical etching from the ion entry side of PC films using a two-cell compartment assembly: (A) $70^{\circ} \mathrm{C}, 30 \mathrm{~min}, \mathrm{NaOH} 2 \mathrm{~N}$ in the first compartment, no neutralizing solution in the last compartment; (B) $70^{\circ} \mathrm{C}, 30 \mathrm{~min}, \mathrm{NaOH} 2 \mathrm{~N}$ in the first compartment, acetic acid solution $15 \mathrm{vol} \%$ in the last compartment.

Figure 7. PC matrix irradiated with low energy ion beam: entry energy of $0.633 \mathrm{Mev} / ? ? ? \mathrm{au}$ - exit energy of $0.1 \mathrm{Mev} /$ ???au. Fluence: $1 \mathrm{e} 8 \mathrm{ions} / \mathrm{cm}^{2}$. Asymmetric etching: $0.1 \mathrm{MeV} / ? ?$ ?au etched face, $70^{\circ} \mathrm{C}, \quad \mathrm{NaOH} \quad 2 \mathrm{~N}, \quad 15 \quad$ min. $\mathrm{Ni}$ electrodeposition. PC matrix is dissolved. Nı $v \alpha v o \omega \imath \rho \varepsilon \sigma \tau \rho \alpha \chi \kappa \rho \varepsilon \pi \lambda \iota \chi \alpha \square: \xi \phi=17 \nu \mu, \alpha=2.3^{\circ}$. 


\section{Table caption}

Table 1. Examples of conical nanopores resulting from PC track-etched membranes etched from 0.1 $\mathrm{MeV} / \mathrm{mau}$.

\begin{tabular}{ccccc}
\hline Temperature $\left({ }^{\circ} \mathrm{C}\right)$ & Etching time $(\min )$ & $\alpha\left(^{\circ}\right)$ & $\mathrm{X}_{\mathrm{i}}(\mathrm{nm})$ & $\mathrm{X}_{f}(\mathrm{~nm})$ \\
\hline 65 & 30 & 1.12 & 350 & 170 \\
70 & 15 & 2.30 & 180 & 17 \\
70 & 20 & 4.15 & 350 & 60 \\
70 & 30 & 13 & 850 & 68 \\
75 & 10 & 2.43 & 465 & 38 \\
\hline
\end{tabular}

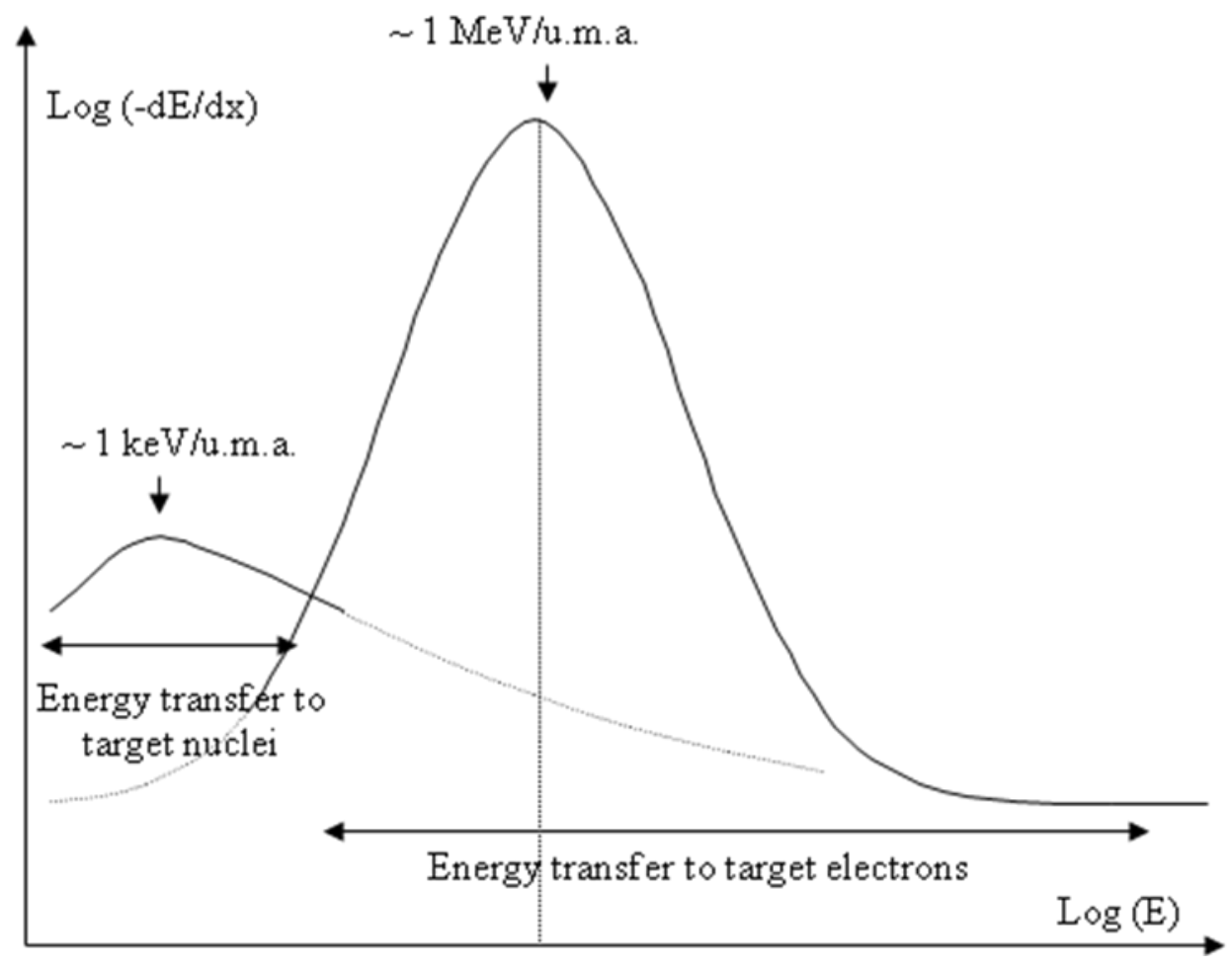

Fig. 1. Schematic stopping function $S(E)$ of a projectile-ion in solid matter as a function of the kinetic energy E of the projectile-ion [14] 


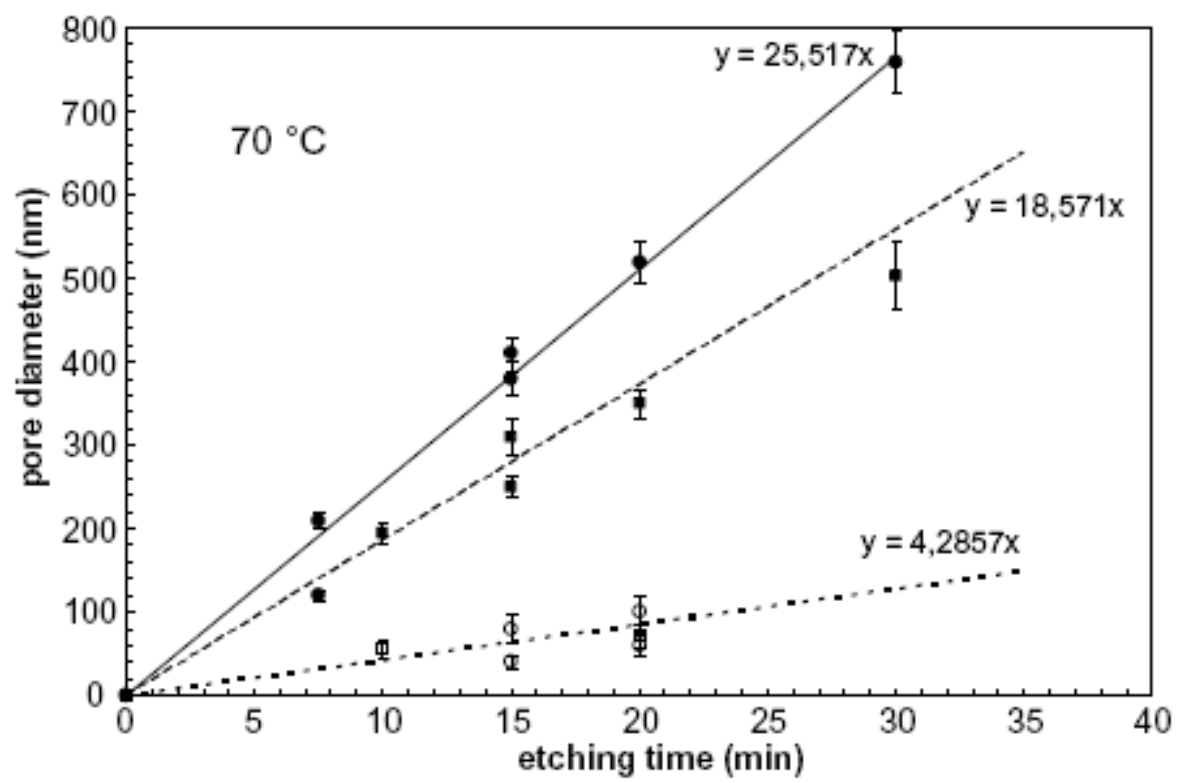

Fig. 2. Pore diameters estimated by SEM versus etching time. Etch conditions: $70^{\circ} \mathrm{C}, \mathrm{NaOH} 2 \mathrm{~N}$. Exit face in contact with etch solution. $\square$ Entry face in contact with water. $\circ$ Exit face in contact with water. Entry face in contact with etch solution. 

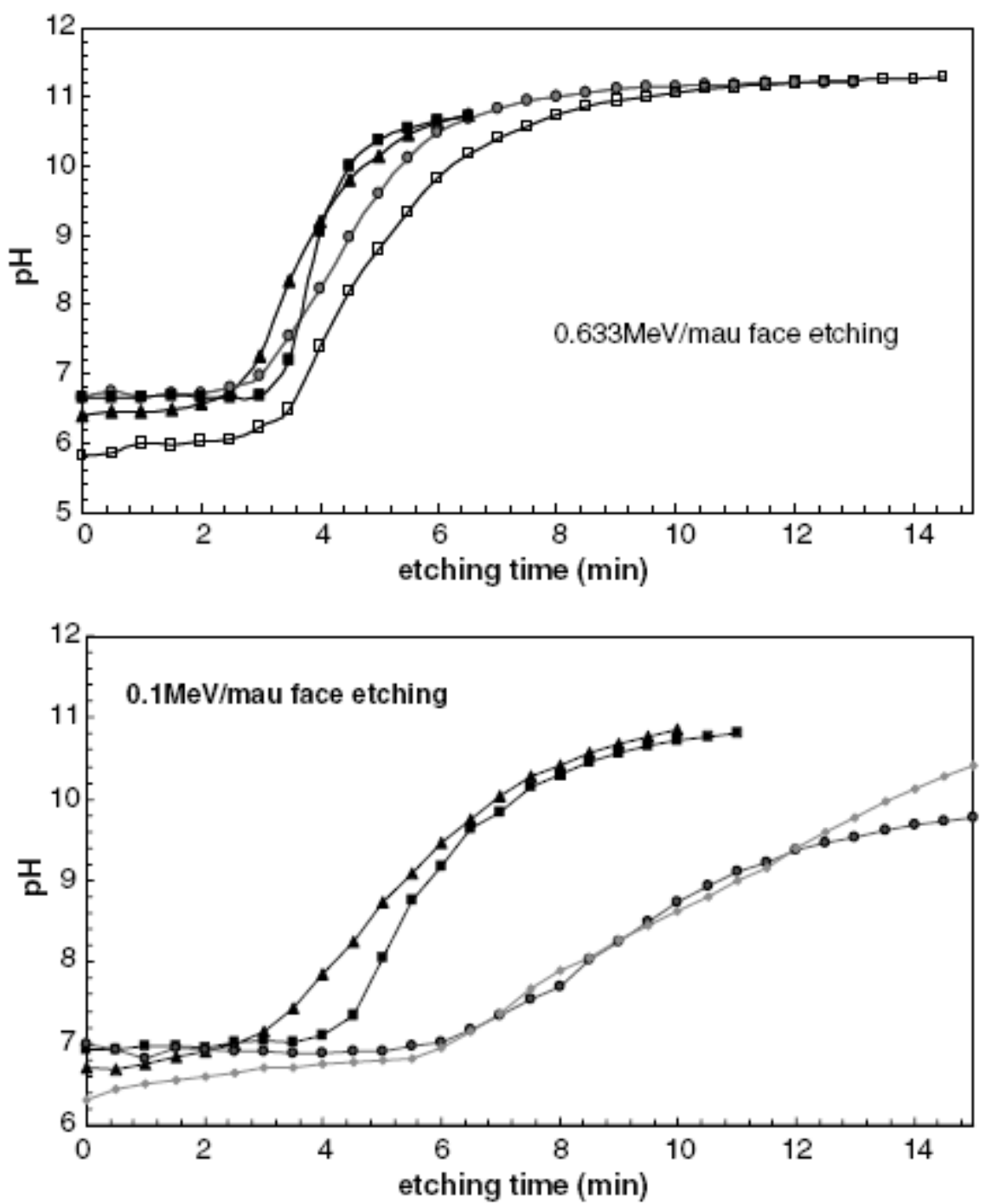

Fig. 3. pH versus etching time curves at $(\square) 65^{\circ} \mathrm{C},(\bullet) 70^{\circ} \mathrm{C},(\boldsymbol{\Delta}) 75^{\circ} \mathrm{C}$ and (ם) $80^{\circ} \mathrm{C}$. 


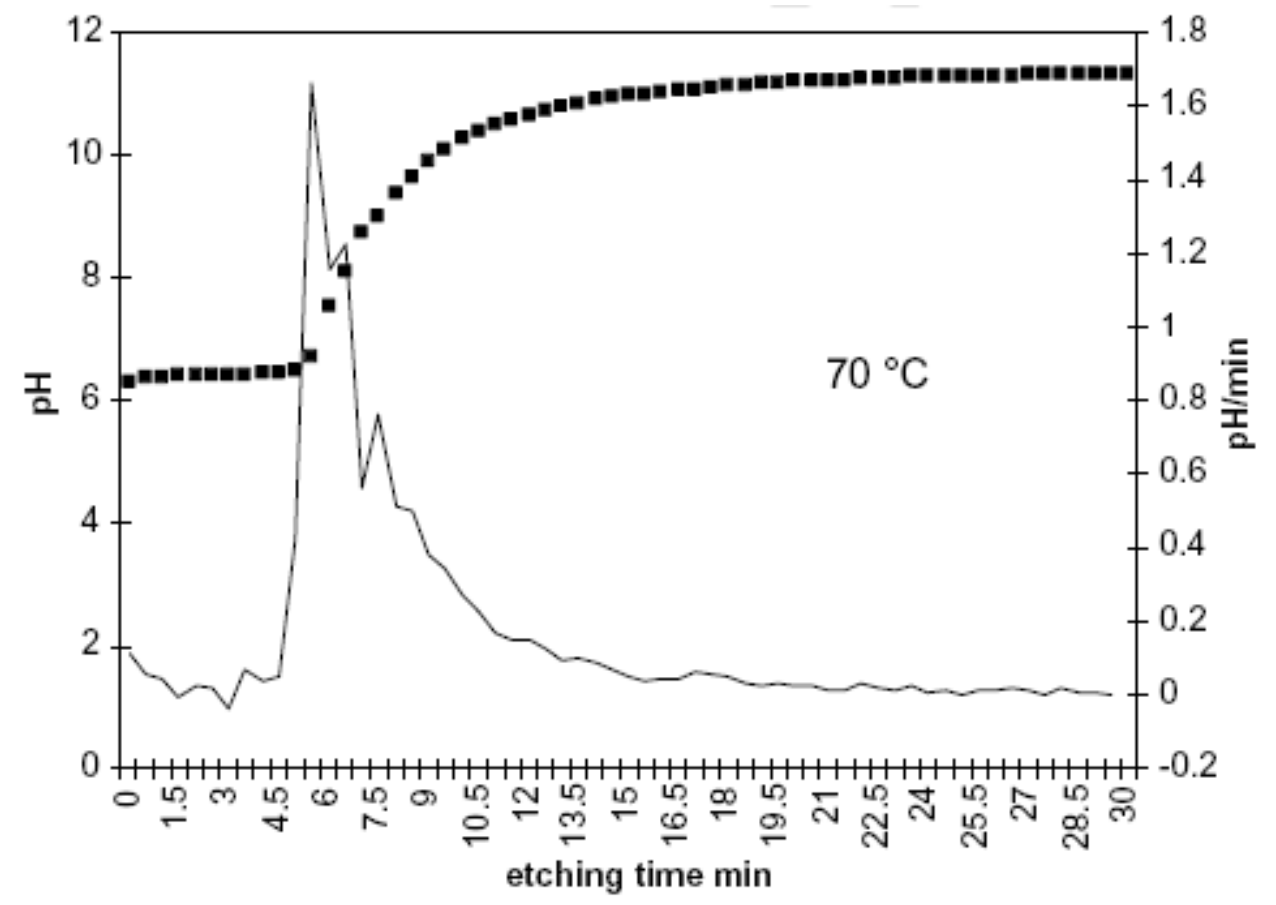

Fig. 4. $\mathrm{pH}$ versus etching time curves of $0.63 \mathrm{MeV} / \mathrm{amu} \mathrm{PC}$ membrane face and its derivative at $70^{\circ} \mathrm{C}$.

a

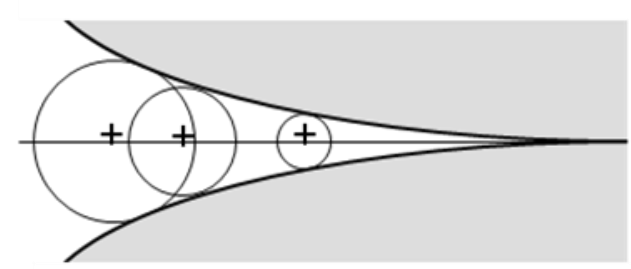

b

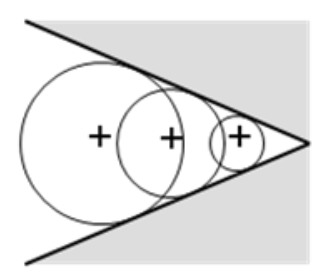

C

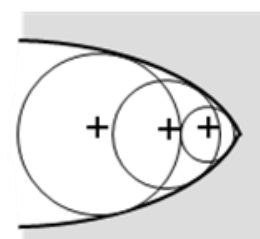

Fig. 5 Typical etch figures for (a) increasing, (b) constant and (c) decreasing etch-rate. The crosses mark the center of the spherical "waves" emitted at equal time intervals [15] 

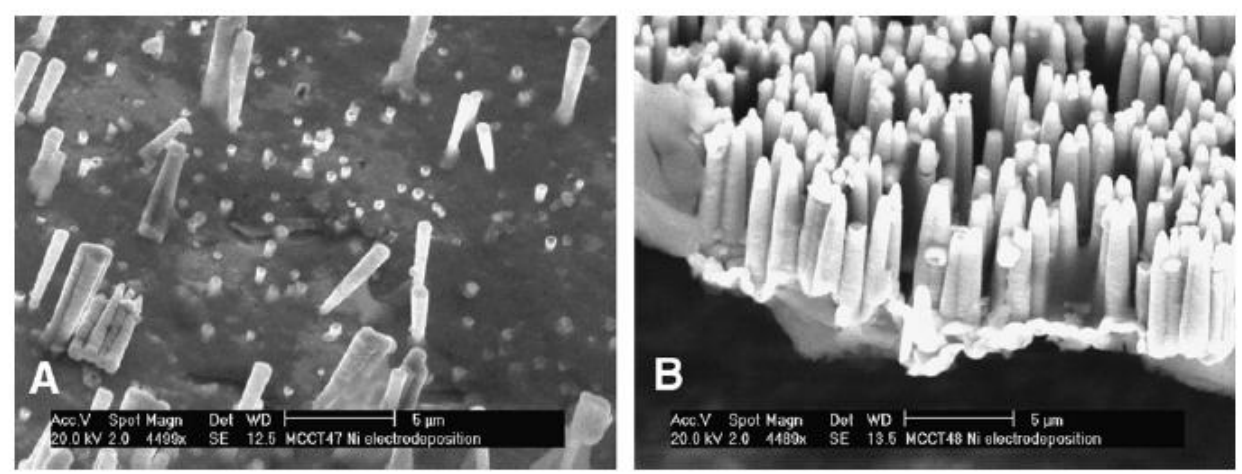

Fig. 6. Electrodeposited Ni conical nanowires (base diameter: $800 \mathrm{~nm}$; top diameter: $100 \mathrm{~nm}$; length $7 \mu \mathrm{m}$ ) after dissolution of metallized track-etched PC membrane. PC films were irradiated with $\mathrm{Pb}$ of $0.63 \mathrm{MeV} / \mathrm{amu}$. Etching conditions: Asymmetrical etching from the ion entry side of PC films using a twocell compartment assembly: (A) $70^{\circ} \mathrm{C}, 30 \mathrm{~min}, \mathrm{NaOH} 2 \mathrm{~N}$ in the first compartment, no neutralizing solution in the last compartment; (B) $70{ }^{\circ} \mathrm{C}, 30 \mathrm{~min}$, $\mathrm{NaOH} 2 \mathrm{~N}$ in the first compartment, acetic acid solution $15 \mathrm{vol} \%$ in the last compartment.

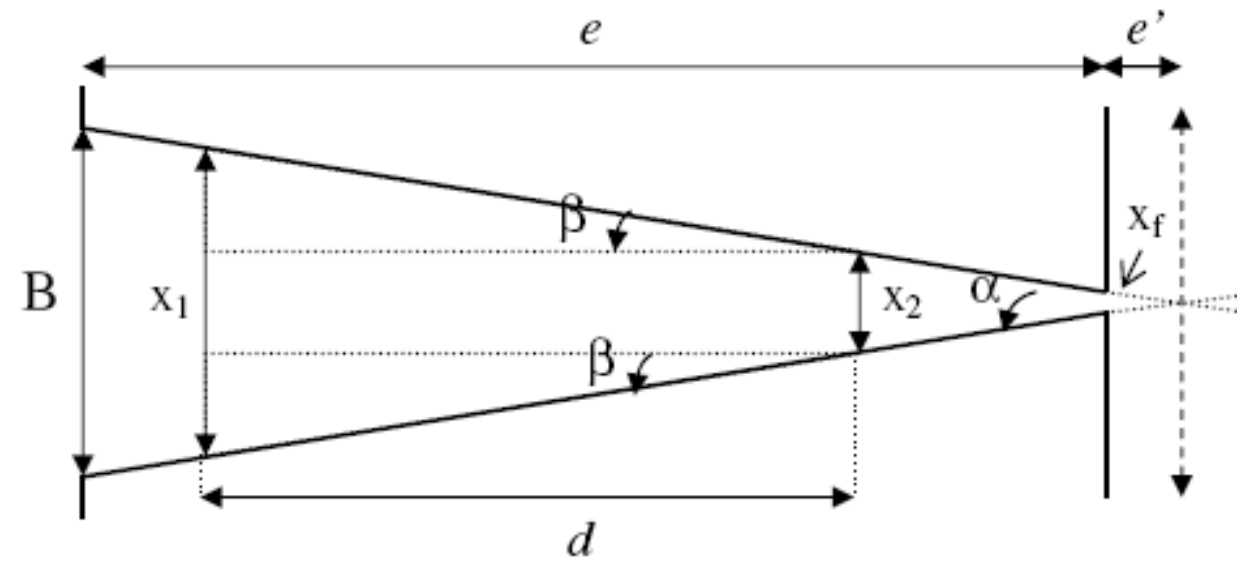

Scheme 1. Geometry of conical pore.
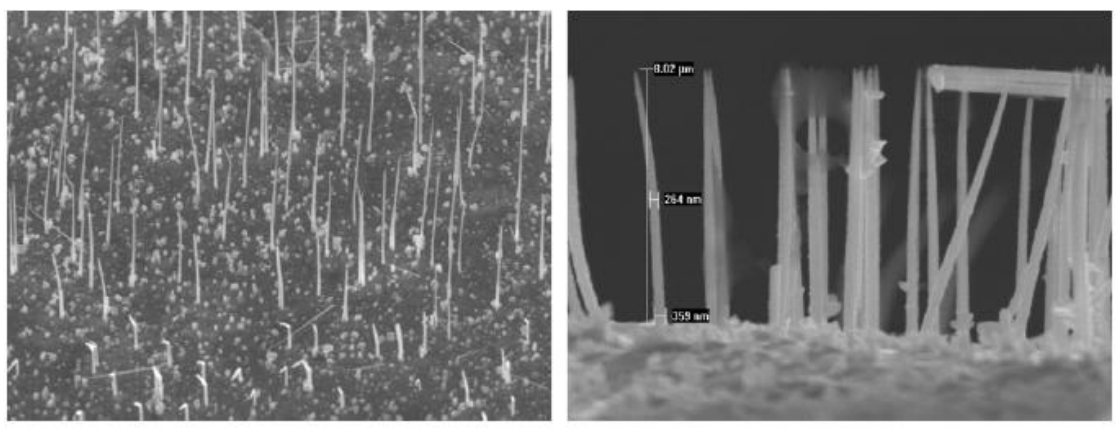

Fig. 7. PC matrix irradiated with low-energy ion beam: entry energy of $0.633 \mathrm{Mev} / \mathrm{amu}$ - exit energy of $0.1 \mathrm{Mev} / \mathrm{amu}$. Fluence: $1 \mathrm{e} 8$ ions/ $\mathrm{cm}^{2}$. Asymmetric etching: $0.1 \mathrm{MeV} / \mathrm{amu}$ etched face, $70^{\circ} \mathrm{C}, \mathrm{NaOH} 2 \mathrm{~N}, 15 \mathrm{~min}$. Ni electrodeposition. PC matrix is dissolved. $\mathrm{Ni}$ nanowires track replica: $\mathrm{X}_{f}=17 \mathrm{~nm}$, $\alpha=2.3^{\circ}$. 